\section{Acute Local Inflammation Alters Synthesis, Distribution, and Catabolism of the Third Component of Complement (C3) in Rabbits}

\author{
Uwe Manthei, Robert C. Strunk, and Patricia C. Giclas \\ Department of Pediatrics, National Jewish Hospital and Research \\ Center, and Departments of Pediatrics and Medicine, University \\ of Colorado Medical School, Denver, Colorado 80206
}

A changes in plasma concentrations of the third component of complement (C3) during inflammation, we injected purified radiolabeled $\mathrm{C} 3$ into normal New Zealand White rabbits and into rabbits with turpentine-induced pleurisy. In the normal animals, C3 was distributed between the intravascular compartment $(75 \%)$ and the extravascular space $(25 \%)$, with an exchange rate of $1.8 \pm 0.1 \%$ of the plasma pool per hour. The fractional catabolic rate (FCR) was $2.7 \pm 0.3 \%$ of the C3 plasma pool per hour, the synthesis rate was $1.0 \pm 0.2 \mathrm{mg} \mathrm{C} 3 / \mathrm{kg}$ per $\mathrm{h}$, and the plasma concentration was $1.23 \pm 0.3 \mathrm{mg} \mathrm{C} 3 / \mathrm{ml}$. Rabbits with turpentine-induced inflammation showed a shift of the volume of C3 distribution in favor of the extravascular compartment. In addition, the rate by which ${ }^{125} \mathrm{I}-\mathrm{C} 3$ was cleared from the circulation increased by $29 \%$ and was related to the appearance of $20 \%$ of the C3-bound circulating radioactivity in the affected pleural cavity at the zenith of inflammation. The FCR, calculated by measuring urinary excretion of radiolabel, increased by only 9\% and was probably related to the C3 degradation that was observed in the pleural fluid during the early stages of inflammation. The plasma C3 concentration reached a peak at $230 \%$ of the baseline concentration, owing to an increase in the rate of synthesis by as much as $480 \%$. The latter increase could be blocked by cycloheximide, an inhibitor of protein synthesis. We conclude that the increase of plasma C3 in the acute phase is due to stimulated synthesis, which is partially offset by a rise in FCR and by a shift of protein to the site of inflammation.

\footnotetext{
Dr. Strunk is the recipient of an Allergic Diseases Academic Award (AI00543).

Received for publication 13 February 1984 and in revised form 2 April 1984.
}

\section{J. Clin Invest.}

(c) The American Society for Clinical Investigation, Inc. 0021-9738/84/08/0424/10 \$1.00

Volume 74, August 1984, 424-433

\section{Introduction}

Acute phase proteins (APPs) ${ }^{1}$ are a group of plasma proteins, the concentrations of which change in response to acute inflammation. The measurement of levels of APP can be helpful in diagnosing and monitoring inflammation, as well as tissue destruction, e.g., myocardial infarction. The third component of complement (C3) is such an APP, since several investigators observed elevations in the plasma $\mathrm{C} 3$ concentration after various inflammatory stimuli in different species. Almost uniformly, a two-fold increase was reported during Schistosoma mansoni infection in mice (1) after intramuscular injection of turpentine into mice (2), and recently in our laboratory after turpentine pleurisy was induced in rabbits. (Giclas, P. C., U. Manthei, B. Thron-Weber, and R. C. Strunk. Manuscript submitted for publication.) Not yet described are the relationships between synthesis rates, the rates of distribution, and the catabolism that lead to the observed plasma C3 level alterations during acute inflammation. Other APPs have been looked at in this respect; after intramuscular injection of turpentine the synthesis rate of rabbit C-reactive protein (CRP) increased 85-fold and the fractional catabolic rate (FCR) remained unchanged (3). Atencio et al. (4) injected rabbits with ACTH and found a three- to ninefold increase in the synthesis rate of fibrinogen but no change in the FCR; the result was a twofold rise in the plasma fibrinogen concentration. Another component of the complement pathway, C9, was identified as an APP in guinea pigs by Takahashi et al. (5) who showed a twofold increase in the plasma level as a result of a fivefold stimulation of the synthesis rate after intramuscular turpentine injection. A possible alteration of the FCR was not examined by these authors.

It is the balance between synthesis, distribution, and catabolism that determines the plasma concentration of any protein at a given time. $\mathrm{C} 3$ is a key protein of the complement pathway and may serve a specific purpose in the inflammatory process. Comparing normal synthesis and metabolic parameters with

1. Abbreviations used in this paper: APP, acute phase protein; C, component of complement; CRP, C-reactive protein; FCR, fractional catabolic rate; NZW, New Zealand White; PCR, plasma clearance rate; RBC, erythrocyte; RSA, rabbit serum albumin; SDS-PAGE, sodium dodecyl sulfate-polyacrylamide gel electrophoresis. 
those rates observed under pathologic conditions may, therefore, give insight into the biological role of this protein and might allow adjustment of therapeutic interventions.

The purpose of this study was to determine, in the rabbit, to what extent locally induced inflammation such as turpentine pleurisy alters the synthesis rate of $\mathrm{C} 3$, the rates of its distribution between various body compartments, and its catabolism.

\section{Methods}

Chemicals and reagents. The following chemicals were purchased from Miles Laboratories, Inc., Research Products Div. (Elkhart, IN): acrylamide, $N, N^{\prime}$-methylenebisacrylamide, ammonium persulfate, $N, N, N^{\prime}, N^{\prime}$ tetramethylethylenediamine, agarose (medium electroendosmosis), and sodium dodecyl sulfate (SDS). ${ }^{125}$ Iodine and ${ }^{131}$ iodine were obtained from New England Nuclear (Boston, MA), Sephadex G75 from Pharmacia Fine Chemicals Inc. (Piscataway, NJ), and the anion exchange resin AG 1-X8 from Bio-Rad Laboratories (Richmond, CA). We purchased Iodo-Gen (1,3,4,6-tetrachloro-3 $\alpha, 6 \alpha$-diphenylglycoluril) from Pierce Chemical Co. (Rockford, IL), 2-mercaptoethanol from Sigma Chemical Co. (St. Louis, MO) trichloroacetic acid (TCA) from Fisher Scientific Co. (Fair Lawn, NJ) human serum albumin from Cutter Laboratories Inc. (Berkeley, CA), and cycloheximide from CalbiochemBehring Corp., American Hoechst Corp. (San Diego, CA). Antibodies to rabbit $\mathrm{C} 3$ and other rabbit plasma proteins were either raised by immunizing goats against the purified component as described in reference 6, or purchased from Nordic Immunological Laboratories (El Toro, CA). The commercial preparations were directed against the rabbit protein with the exception of anti-CRP and anti-ceruloplasmin (ATAB, Scarborough, ME), which were directed against the human equivalent but known to cross-react with the rabbit species. Rabbit C3 hemolytic activity was measured in plasma samples according to Giclas et al. (6), and $\mathrm{C} 3$ antigen was measured with goat anti-rabbit $\mathrm{C} 3$, either by radial immunodiffusion (7) or rocket immunoelectrophoresis (8).

TCA precipitation. All precipitations of radiolabelled, purified C3 in both plasma and urine were carried out at a final concentration of $10 \%$ TCA in the presence of $20 \%$ normal rabbit serum as carrier protein.

C3 preparation. Rabbit C3 was purified by the method of Giclas et al. (6) which includes the addition of inhibitors of C3-cleaving enzymes throughout the entire process. Immunodiffusion against antibodies to rabbit immunoglobulins, C3, C5, C6, factor $\mathrm{H}, \mathrm{CRP}$, ceruloplasmin, and albumin showed that the final product reacted only with anti-C3. It migrated as one band with an apparent molecular weight (Mr) of 180,000 in SDS-polyacrylamide gel electrophoresis (SDS-PAGE). Two subunits with $\mathrm{Mr}$ of 70,000 and 120,000 , respectively, were observed on SDS-PAGE after reduction with 5\% 2-mercaptoethanol. The purified preparation showed a single arc by crossed immunoelectrophoresis into agar containing goat anti-whole rabbit serum. The specific hemolytic activity was $1.2 \times 10^{10}$ effective molecules/mg protein, comparable to the specific activity of $\mathrm{C} 3$ in the purification procedure described by Giclas et al. (6).

Radioiodination. ${ }^{125} \mathrm{I}$ or ${ }^{131} \mathrm{I}$ was covalently linked to $\mathrm{C} 3$ or rabbit serum albumin (RSA) by a modification of the Iodo-Gen method (9). Glass vials, precoated with $20 \mu \mathrm{g}$ of Iodo-Gen reagent also containing $0.5 \mathrm{~g}$ of Iodo-Gen-coated glass beads, were thoroughly washed with 0.2 $\mathrm{M}$ potassium phosphate buffer, $\mathrm{pH}$ 7.3. $100 \mu \mathrm{l}$ of the buffer remained in the vial when $100 \mu \mathrm{l}$ phosphate buffered saline (pH 7.3) containing $100 \mu \mathrm{g}$ purified $\mathrm{C} 3$ was added. $0.5-1.0 \mathrm{mCi}$ of ${ }^{125} \mathrm{I}$ or ${ }^{131} \mathrm{I}$ was added and allowed to react for $30 \mathrm{~min}$ at $4^{\circ} \mathrm{C}$ with repeated gentle mixing. The mixture then was passed through glass wool and Sephadex G75 to remove the glass beads and was collected in a tube containing $100 \mu \mathrm{l}$ of $1 \mathrm{M}$ potassium iodide (final dilution $0.25 \mathrm{M}$ ) to stop the binding process. The unbound iodine was removed by passage through $\sim 2 \mathrm{~g}$ of the anion exchange resin AG 1-X8. TCA, 10\% final concentration, consistently precipitated more than $96 \%$ of the remaining radioactivity. The specific activity of the labeled $\mathrm{C} 3$ preparations ranged from 0.36 to $2.4 \mathrm{mCi} / \mathrm{mg}$ protein. When ${ }^{125} \mathrm{I}-\mathrm{C} 3$ was mixed with serum samples and activated by the addition of immune complexes, the radioactive preparation was cleaved in the same way as the unlabeled $\mathrm{C} 3$ fraction of the serum, as indicated by crossed immunoelectrophoresis against anti-rabbit $\mathrm{C} 3$. Comparing hemolytic titers before and after iodination, however, we noticed a decrease of specific hemolytic activity (effective molecules per milligram protein) of up to $35 \%$. This is similar to what Ruddy et al. (10) observed in their studies.

In vivo studies with $C 3$. Before injection, the ${ }^{125} \mathrm{I}-\mathrm{C} 3$ was diluted in sterile pyrogen-free human serum albumin ( $5 \%$ in saline), filtered through a $0.2 \mu \mathrm{m}$ Millipore filter (Gelman Sciences, Inc., Ann Arbor, MI) and injected not later than $16 \mathrm{~h}$ after labeling. Volumes of $1-2 \mathrm{ml}$ were injected into the marginal ear veins of eight New Zealand White (NZW) rabbits $(3.4 \pm 0.5 \mathrm{~kg})$. The exact amount of injected radioactivity was determined by counting a $10-\mu \mathrm{l}$ aliquot of the preparation and multiplying by the quantity injected as determined by the difference in weight of the empty and full syringe. Whatever remained in the syringe, needle, and tubing was subtracted. These calculations were needed for the determination of the ratio between urinary excretion and remaining plasma activity.

Blood samples $(0.7-1.2 \mathrm{ml})$ were withdrawn by puncture of the ear artery without the use of xylene and collected into standard EDTAcontaining tubes (3-ml purple top vacutainer tubes; Becton Dickinson and Co., Rutherford, NJ) and counted in a gamma counter (model 7000; Beckman Instruments, Inc., Irvine, CA). The first sample was withdrawn at 15 min postinjection to allow equal distribution of the ${ }^{125} \mathrm{I}-\mathrm{C} 3$ in the circulation. Blood volumes were calculated by assuming that the first sample represented total distribution of the entire labeled protein in the circulation. The results obtained by this procedure correlated well with the blood volumes measured by the ${ }^{59} \mathrm{Fe}$-erythrocyte (RBC) dilution method (11), performed $24 \mathrm{~h}$ before the ${ }^{125} \mathrm{I}-\mathrm{C} 3$ turnover study in four rabbits. All subsequent measurements were expressed as fraction of the first sample. Curves representing whole blood were identical to those obtained by counting plasma only or TCA precipitates of plasma. More than $96 \%$ of the radioactivity appeared in the TCA precipitates of the plasma at all time points.

The rabbits were kept in metabolic cages where their only source of drinking water contained $30 \mathrm{mg} /$ liter of potassium iodide to block ${ }^{125}$ I uptake by the thyroid glands, and $90 \mathrm{mg} /$ liter of sodium chloride to stimulate thirst and subsequent diuresis. The urinary radioactivity was measured for each 24-h period and expressed as a fraction of the total injected activity. Precipitation of the urine with TCA showed that less than $5 \%$ of the radioactivity was bound to protein. The total body radioactivity was calculated by subtracting the cumulative urinary excretion of ${ }^{125} \mathrm{I}$ from the total amount injected.

Turpentine pleurisy was induced and monitored as described by Sahn and Potts (12) and by Giclas et al. (Giclas, P. C., U. Manthei, B. Thron-Weber, and R. C. Strunk. Manuscript submitted for publication.) Pleural fluid was obtained by thoracentesis with a 23-g hypodermic needle through the right seventh posterolateral intercostal space.

Analysis of data. The radioactivity remaining in the rabbits' circulation was plotted as the log of the fraction of the 15-min reference value on the ordinate against a linear abscissa expressing the time. The equation that provides the best fit for such curves is (13): $y=C_{1} \mathrm{e}^{-b_{11}}$ $+C_{2} \mathrm{e}^{-b_{22} t}+\cdots+C_{n} \mathrm{e}^{-b_{n} t}$, where $n$ represents the number of linear plots to which the observed graph can be reduced, $C_{1}$ marks the $y$ - 
intercept, and $b_{1}$ is the slope of each individual linear plot (13); in this equation, $n$ can also be interpreted as the number of compartments into which the injected compound is distributed.

Based on previous work by Mathews (13), Atencio and Reeve $(14,15)$ and Reeve and Chen $(16)$, the FCRs were calculated by the following equation:

$\mathrm{FCR}=\left(\frac{C_{1}}{b_{1}}+\frac{C_{2}}{b_{2}}+\cdots+\frac{C_{\mathrm{n}}}{b_{\mathrm{n}}}\right)^{-1}$,

i.e., the fraction of the plasma pool catabolized per hour. This method is based on analysis of the disappearance of radioactivity from the circulation only. Ruddy et al. (10) reviewed data from turnover studies of radiolabeled complement protein in normal volunteers to establish the parameters during steady state. They recognized a rapidly cleared fraction of the iodinated $\mathrm{C} 3$ and were able to show a positive correlation between the size of this fraction and the loss of specific hemolytic activity of the individual preparation before injection. This inactivation was present even though polyacrylamide gel disc electrophoresis, immunoelectrophoresis, or immunoprecipitation had failed to demonstrate contaminants or alterations in the $\mathrm{C} 3$ preparations. In findings similar to those of Ruddy et al. (10), we have observed a rapidly cleared fraction in all our animals. For example, in one study a $35 \%$ loss of specific hemolytic activity measured after the iodination procedure was associated with rapid clearance of $16 \%$ of the total injected radioactivity. Biological screening of ${ }^{125} \mathrm{I}-\mathrm{C} 3$ in donor rabbits for $24 \mathrm{~h}$ before injection into the recipient animals was done in two experiments, by methods similar to those of Charlesworth et al. (17) (rabbits 5 and 6, Table I). The results in the two recipient rabbits demonstrated that the biological screening failed to remove the fast compartment $(16.4 \pm 4.6 \%, n=2$ vs. $24.2 \pm 6.9 \%$, $n=6$ ). Ruddy and co-workers recommended that the clearance curves be normalized to two exponents by subtracting the rapidly cleared fraction from the total injected and by replotting the difference. In accordance with this recommendation, all curve analysis data presented in this paper have been calculated after correction of the ${ }^{125} \mathrm{I}-\mathrm{C} 3$ clearance curves to two exponents.

When the urinary ${ }^{125} \mathrm{I}$ activity $(\bar{U})$ for a given time $(t)$ period (in hours) is expressed as fraction of the mean plasma activity $(\bar{X})$ for the same time period, it represents the FCR for this period. The following equation was used to determine the urine-plasma derived FCR:

$\mathrm{FCR}_{(\bar{U} / \bar{X})}=\frac{\bar{U}_{t}}{\bar{X}_{t}} t^{-1}$,

i.e., the fraction of the plasma pool catabolized per hour.

Fig. 1 shows the model described by Atencio and Reeve $(14,16)$ that we used in a modified version for our calculations. The coefficients for the exchange rates between the compartments $\left(j_{1}\right.$ and $j_{2}$, see Fig. 1) were determined according to Atencio's (14) and Reeve's (16) equations:

$j_{1}=C_{1} b_{1}+C_{2} b_{2}-(\mathrm{FCR})$

and

$j_{2}=C_{1} b_{2}+C_{2} b_{1}$.

The extravascular volume of $\mathrm{C} 3$ distribution $(\bar{Y})$ was determined as a fraction of the intravascular space from the equation (14):

$\bar{Y}=\frac{j_{1}}{j_{2}} \bar{X}$.

During steady state the synthesis rate $\left(Q_{0}\right)$ equals the FCR. The absolute value can be calculated by the equation:

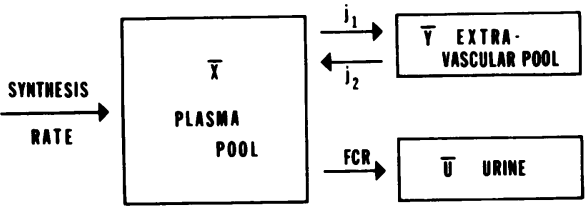

Figure 1. Two-compartment model for the distribution of C3. FCR during the steady state equals the synthesis rate. $j_{1}$ and $j_{2}$ are the exchange coefficients between the intra- and extravascular compartments.

$Q_{0}=$ FCR $\times \bar{P} \times c_{0}$

$\left(\bar{P}\right.$, plasma volume [milliliters per kilogram]; $c_{0}, \mathrm{C} 3$ plasma concentration [milligrams per milliliter]). Atencio and Reeve $(4,14)$ have presented the equations that can be used to calculate synthesis rates when a change in the plasma concentration occurs.

$Q_{1}=\frac{\mathrm{FCR} \times \bar{P}\left(t_{1}-t_{0}\right) \times \frac{c_{0}+c_{1}}{2}+\mathrm{d}\left(c_{1}-c_{0}\right) \bar{P}}{t_{1}-t_{0}}$

in milligrams per kilogram per hour, where $t_{0}=$ time when initial steady state is left, $t_{1}=$ time when new steady state is reached (hours), $c_{0}$ = plasma concentration at initial steady state (milligrams per milliliter), $c_{1}=$ plasma concentration at new steady state (milligrams per milliliter), $\mathrm{d}=$ factor of the total body distribution. $\mathrm{d}=1+j_{1} / j_{2}$, or 1.31 , for the steady state (mean of all rabbits).

As will be shown later, a change in the FCR and the total body distribution factor occurred during turpentine pleurisy. Since the clearance rate of the iodinated $\mathrm{C} 3$ from the circulation represents the sum of catabolism and unidirectional accumulation in the newly created compartment, the pleural cavity, the term FCR is no longer applicable, and the rate of clearance from the circulation was therefore redefined as plasma clearance rate (PCR). For the calculation of $\mathrm{C} 3$ synthesis rates during different periods of the inflammatory process, we used the plasma C3 concentrations, PCRs, and distribution factors calculated for the period of inflammation.

Statistics. The C3 clearance curves were analyzed by initial curve fitting according of the method of Foss (18) followed by least squares estimation of the nonlinear parameters (19).

\section{Results}

Studies in normal rabbits. Since C3 metabolism in the rabbit has not been studied with purified rabbit $\mathrm{C} 3$, initial studies were performed to establish the constants for $\mathrm{C} 3$ turnover during the steady state in normal animals. The mean plasma $\mathrm{C} 3$ concentration in our animals $(n=8)$ was $1.23 \pm 0.3 \mathrm{mg} / \mathrm{ml}(\mathrm{SD})$ and the mean plasma volume was $31.5 \pm 3.5 \mathrm{ml} / \mathrm{kg}(\mathrm{SD})$, as determined by the ${ }^{59} \mathrm{Fe}-\mathrm{RBC}$ and the ${ }^{125} \mathrm{I}-\mathrm{C} 3$ dilution methods. Fig. 2 shows the means and standard deviations of total body radioactivity, $\mathrm{PCR}$, and urinary excretion of ${ }^{125} \mathrm{I}-\mathrm{C} 3$ for eight $\mathrm{NZW}$ rabbits before subtraction of the rapidly removed fraction. The ${ }^{125} \mathrm{I}-\mathrm{C} 3$ clearance curves and two corresponding linear plots after normalization to fit the two-compartment model based on data obtained from eight normal rabbits are depicted in Fig. 3. Table I lists the individual parameters for each animal. 


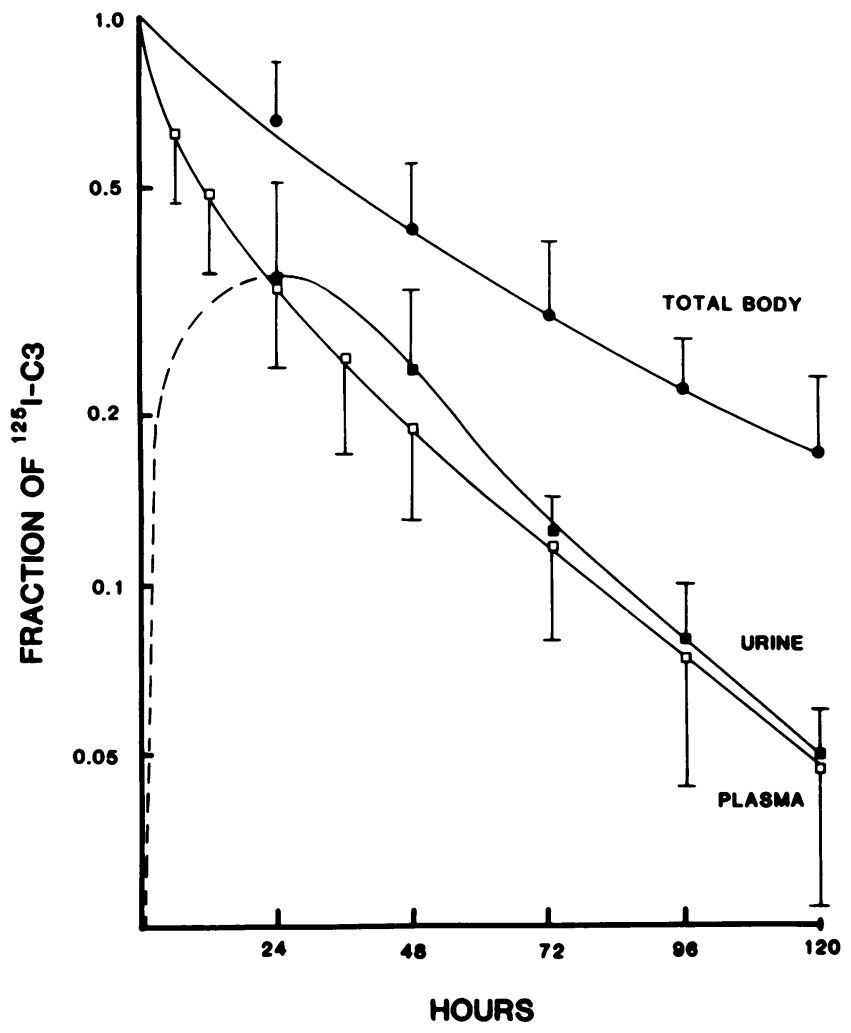

Figure 2. Total body radioactivity, urinary excretion, and plasma clearance curves of ${ }^{125} \mathrm{I}-\mathrm{C} 3$ in eight normal NZW rabbits plotted as a fraction of the total injected radioactivity before removal of the rapidly cleared fraction (mean \pm SD). The total body radioactivity was calculated by subtraction of the cumulative urinary activity from the total injected amount.

The FCRs were calculated by the curve analysis method as well as by the ratio between urinary excretion and mean plasma activity. Both methods gave similar results during normal steady state conditions (Table II, Fig. 3). The synthesis rate of $2.7 \pm 0.3 \%$ of the plasma pool per hour $(1.05 \mathrm{mg} / \mathrm{kg}$ per $\mathrm{h})$ maintained constant levels for a daily turnover of almost $50 \%$ of the total body C3 pool of the rabbit $(51.5 \mathrm{mg} / \mathrm{kg}$ per d). The ratio of 1:0.31 between the circulation and the extravascular space [ $\left(j_{1} / j_{2}\right)$, Table I] indicates that during the steady state $25 \%$ of the total body $\mathrm{C} 3$ was found in the extravascular compartment, compared with $75 \%$ in the circulation.

Studies in rabbits with inflammation. To determine what effect acute inflammation had on $\mathrm{C} 3$ metabolism, ${ }^{125} \mathrm{I}-\mathrm{C} 3$ was injected into four rabbits, and the steady state was documented at $72 \mathrm{~h}$ by a linear clearance curve with a slope representing the previously established half-life of $\sim 40 \mathrm{~h}$. At this point, pleurisy was induced by injecting turpentine into the pleural space. Fig. 4 shows that during the initial $24 \mathrm{~h}$ after the induction of inflammation, $\sim 20 \%$ of the circulating ${ }^{125} \mathrm{I}-\mathrm{C} 3$ pool was cleared from the intravascular space. The rate of disappearance was approximately twice as fast as the half-life during steadystate, and radioactivity lost from the circulation could not be

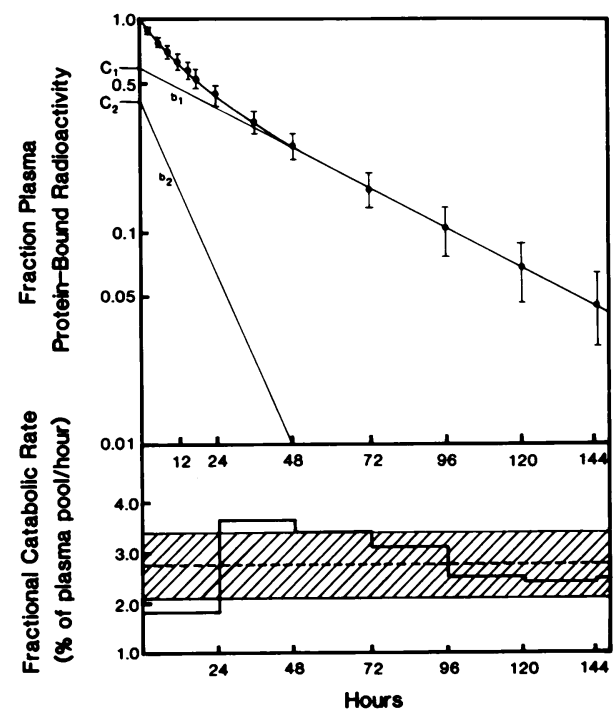

Figure 3. Curve analysis (top) and urine-plasma $(\bar{U} / \bar{X})$ ratio (FCR, bottom) data from eight NZW rabbits after removal of the rapidly cleaved fraction (compare with Fig. 2). $C_{\mathrm{n}}$ represents the fraction of total body radioactivity in the intravascular $\left(C_{1}\right)$ and the extravascular $\left(C_{2}\right)$ compartment (see Table III). $b_{1}$, the slope of the clearance curve at steady state, is a measure for the catabolism of ${ }^{125} \mathrm{I}-\mathrm{C} 3$, and $b_{2}$ is a measure for the exchange between the intravascular and extravascular compartments. The hatched area shows the mean and standard deviation of the FCR.

recovered in urine. To examine the site of redistribution of the plasma C3, one rabbit was killed $24 \mathrm{~h}$ after the simultaneous induction of pleurisy and injection of two radiolabeled compounds, ${ }^{125} \mathrm{I}-\mathrm{C} 3$ and ${ }^{131} \mathrm{I}-\mathrm{RSA}$. Of the ${ }^{125} \mathrm{I}-\mathrm{C} 3$ activity, $19.2 \%$ was found in the pleural cavity with $20.3 \%$ of the ${ }^{131}$ I-RSA, suggesting that the redistribution of $\mathrm{C} 3$ into the inflammatory site was entirely responsible for the loss of activity from the circulation. In addition, the initial redistribution was not unique to C3, for albumin entered the pleural space as easily as C3.

To define more precisely the effect of inflammation, two rabbits were used as their own controls for measuring $\mathrm{C} 3 \mathrm{me}-$ tabolism in the normal state with ${ }^{125} \mathrm{I}-\mathrm{C} 3$ and metabolism during inflammation after injection of ${ }^{131} \mathrm{I}-\mathrm{C} 3$. The curve analyses and $\bar{U} / \bar{X}$ ratios of both preparations were then compared with each other after correction for the different isotope decay rates (Table III). The results again suggested that radiolabeled C3 was redistributed from the circulation into the extravascular space. In particular, $C_{1}, C_{2}$, and $j_{1} / j_{2}$, three parameters of the curve analyses, describe the distribution of $\mathrm{C} 3$ in the two compartments. $C_{1}$, an indicator of the intravascular space, declined, whereas $C_{2}$ increased, representing an extravascular gain. The ratio between the two compartments $\left(j_{1} / j_{2}\right)$ also changed in favor of the extravascular space. Table III also shows a $30 \%$ increase of the PCR during pleurisy compared with normal based on the curve analysis method. The FCRs based on the $\bar{U} / \bar{X}$ ratios showed only a $9 \%$ increase when compared with control. Whereas the values for $C_{1}, C_{2}, b_{1}, b_{2}, j_{1} / j_{2}$, and $\bar{U} / \bar{X}$ 
Table I. Parameters of C3 Metabolism in Eight NZW Rabbits from Curve Analysis (Two-Compartment Model)

\begin{tabular}{|c|c|c|c|c|c|c|c|c|}
\hline \multirow[b]{2}{*}{ Rabbit } & \multicolumn{4}{|c|}{ Parameters of the curve analysis } & \multirow[b]{2}{*}{ FCR } & \multicolumn{3}{|c|}{$\begin{array}{l}\text { Parameters for the exchange between } \\
\text { compartments }\end{array}$} \\
\hline & $C_{1}$ & $b_{1}$ & $C_{2}$ & $b_{2}$ & & $j_{1}$ & $j_{2}$ & $j_{1} / j_{2}$ \\
\hline 1 & 0.5968 & 0.0164 & 0.4014 & 0.1026 & 0.0248 & 0.0262 & 0.0678 & 0.39 \\
\hline 2 & 0.7704 & 0.0214 & 0.2347 & 0.0987 & 0.0261 & 0.0136 & 0.0811 & 0.17 \\
\hline 3 & 0.3151 & 0.0170 & 0.6870 & 0.0520 & 0.0315 & 0.0096 & 0.0281 & 0.34 \\
\hline 4 & 0.4876 & 0.0178 & 0.5177 & 0.0904 & 0.0302 & 0.0253 & 0.0533 & 0.47 \\
\hline 5 & 0.6316 & 0.0184 & 0.3634 & 0.0425 & 0.0233 & 0.0037 & 0.0335 & 0.11 \\
\hline 6 & 0.5911 & 0.0228 & 0.4104 & 0.0529 & 0.0297 & 0.0055 & 0.0406 & 0.14 \\
\hline 7 & 0.5247 & 0.0142 & 0.4523 & 0.0719 & 0.0231 & 0.0167 & 0.0441 & 0.38 \\
\hline 8 & 0.5645 & 0.0154 & 0.4350 & 0.1240 & 0.0249 & 0.0377 & 0.0767 & 0.49 \\
\hline Mean & 0.5602 & 0.0179 & 0.4377 & 0.0794 & 0.0267 & 0.0173 & 0.0532 & 0.31 \\
\hline SD & 0.1299 & 0.0029 & 0.1296 & 0.0290 & 0.0033 & 0.0117 & 0.0200 & 0.15 \\
\hline
\end{tabular}

$C_{\mathrm{n}}$ are the $y$-intercepts and $b_{\mathrm{n}}$ are the slopes of the two linear plots of each clearance curve. The FCRs are calculated from these values by Eq. 1 , $j_{1}$ and $j_{2}$ are the coefficients for the intercompartmental exchange and are calculated according to Eq. 3 and $4 . j_{1} / j_{2}$ represents the ratios between the intravascular and extravascular space of $\mathrm{C} 3$ distribution.

ratio in the turpentine-injected animals fall within $1 \mathrm{SD}$ of the eight normal rabbits (Table I), the changes in the PCR were greater than $1 \mathrm{SD}$.

The typical response to turpentine pleurisy in NZW rabbits is a 2.3-fold rise of the total plasma C3 concentration, as has previously been shown by our laboratory. (Giclas, P. C., U. Manthei, B. Thron-Weber, and R. C. Strunk. Manuscript submitted for publication.) To determine whether this increase in C3 concentration was due to neosynthesis or redistribution of preformed protein, synthesis was blocked in vivo by cycloheximide injection in dosages that are known to inhibit protein synthesis in rabbits (16). Fig. 5 shows the response of rabbits to $15 \mathrm{mg} / \mathrm{kg}$ of cycloheximide, with and without the induction of turpentine pleurisy. Inflammation only was induced in group 1 , and the typical elevation of the plasma $\mathrm{C} 3$ concentration was seen at $24 \mathrm{~h}$. When the inhibitor was injected at the same time as turpentine, a decline of the plasma $\mathrm{C} 3$ concentration was noted after a lag period of $6 \mathrm{~h}$ (group 3). The same pattern was

Table II. FCR and Synthesis Rates from Curve Analysis and Urine Plasma Ratios

\begin{tabular}{llll}
\hline Method & FCR & Synthesis rate & Synthesis rate \\
\hline & $\begin{array}{l}\text { fraction of plasma } \\
\text { pool/h }\end{array}$ & $\mathrm{mg} / \mathrm{kg} / \mathrm{h}$ & $\mathrm{mg} / \mathrm{kg} / \mathrm{d}$ \\
& $0.0267 \pm 0.0033$ & 1.03 & 24.8 \\
Curve analysis & $0.0275 \pm 0.0065$ & 1.07 & 25.6 \\
$\bar{U} / \bar{X}$ & & &
\end{tabular}

$\bar{U} / \bar{X}$ is the ratio between the urinary excretion of ${ }^{125} I$ and the mean plasma activity during the same time period. Synthesis rates were calculated according to Eq. 6 using a mean plasma volume of $31.5 \pm 3.5$ $\mathrm{mg} / \mathrm{kg}$ (whole blood volume $=51.5 \pm 3 \mathrm{ml}$, hematocrit $=37.5 \pm 2.5 \%$ ) and a C3 concentration of $1.23 \pm 0.3 \mathrm{mg} / \mathrm{ml}$. observed in animals that received cycloheximide only (group 4). When the drug was injected $12 \mathrm{~h}$ after the induction of pleurisy (group 2), an increase in the C3 level was observed between 12 and $18 \mathrm{~h}$, similar to that seen in the rabbits of group 1. However, after $18 \mathrm{~h}$ ( $6 \mathrm{~h}$ after cycloheximide) a fall in the plasma C3 level occurred parallel to that observed in groups 3 and 4. Linear regression of the coordinates of groups 3 and 4 at 6,12 , and $24 \mathrm{~h}$ with the methods described for ${ }^{125} \mathrm{I}-\mathrm{C} 3$ showed that the plasma C3 concentrations declined with a half-life of $39 \mathrm{~h}$ after total blockade of protein synthesis, similar to the halflife calculated after injection of ${ }^{125} \mathrm{I}-\mathrm{C} 3$, i.e., $40 \pm 6 \mathrm{~h}$.

After it was established that changes in plasma $\mathrm{C} 3$ concentration were due in part to increased neosynthesis, an attempt was made to calculate synthesis rates for individual time periods

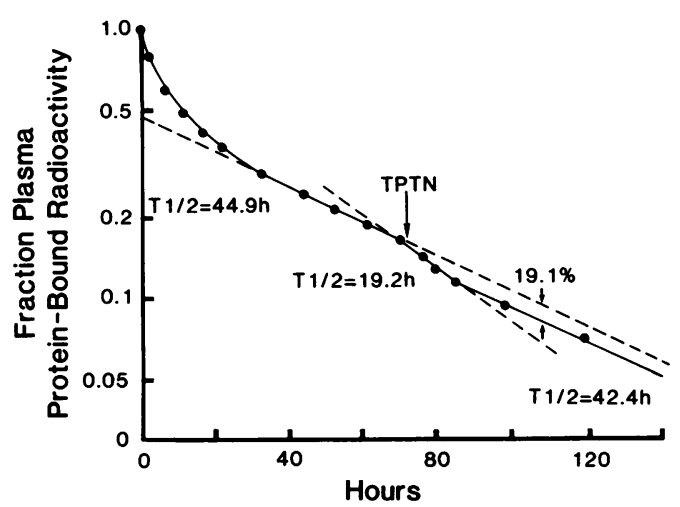

Figure 4. Plasma clearance curve of ${ }^{125} \mathrm{I}-\mathrm{C} 3$ resulting from injection of turpentine (TPTN) into rabbits that had reached steady state (72 h). During the first $24 \mathrm{~h}$ after TPTN, $\sim 20 \%$ of the circulation radioactivity is cleared twice as fast as in the steady state. After $24 \mathrm{~h}$ the clearance rate is back to normal. 
Table III. The Changes of C3 Metabolism during Turpentine Pleurisy

\begin{tabular}{lccccr}
\hline & \multicolumn{1}{c}{$C_{1}$} & \multicolumn{1}{c}{$C_{2}$} & \multicolumn{1}{c}{ PCR } & \multicolumn{1}{l}{$\bar{U} / \bar{X}$} & \multicolumn{1}{c}{$j_{1} / j_{2}$} \\
\hline Normal & 0.54 & 0.44 & 0.024 & 0.023 & 0.44 \\
Pleurisy & 0.43 & 0.57 & 0.031 & 0.025 & 0.53 \\
\% change & -23 & +29 & +29 & +9 & +20
\end{tabular}

$C_{1}$ and $C_{2}$ are the $y$-intercepts of the linear plots in the two-compartment curve analysis method. The PCR is the sum of the catabolism and the shift into the pleural space (see Fig. 2), and represents the fraction of the total body radioactivity in the intravascular $\left(C_{1}\right)$ and extravascular $\left(C_{2}\right)$ compartments. The $\bar{U} / \bar{X}$ is the fraction of circulating radioactivity excreted in $24 \mathrm{~h}$ and represents the FCR. The ratio between the intra- and extravascular spaces is expressed by $j_{1} / j_{2}$.

throughout the course of the inflammation. Unlike the results of an injection of ACTH as a stimulus of fibrinogen synthesis (4), in our model of turpentine pleurisy an accelerated clearance rate of ${ }^{125} \mathrm{I}-\mathrm{C} 3$ from the circulation accompanied by a simultaneous shift into the extravascular compartment was observed. Since the synthesis rate has to compensate for accelerated clearance from the circulation, we replaced the FCR with the PCR (Eq. 7) and used 1.53 (Table III) as factor for the total body distribution instead of 1.44 (rabbits 7 and 8). This permitted characterization of the distribution between the two compartments in the same rabbits during steady state (Table III). Fig. 6 shows that with these assumptions a synthesis rate equal to $480 \%$ of baseline was calculated for the first $24 \mathrm{~h}$ after turpentine injection. This was reflected in a $60 \%$ increase in the plasma C3 concentration between 12 and $24 \mathrm{~h}$. After this initial spike, the synthesis rate continuously decreased throughout the course of inflammation. The corresponding plasma $\mathrm{C} 3$ concentrations are also shown in Fig. 6.

C3 activation. After the activation of $\mathrm{C} 3$, some $\mathrm{C} 3$ fragments formed can enhance the inflammatory response. To determine whether activation occurred in the pleural exudate, a process

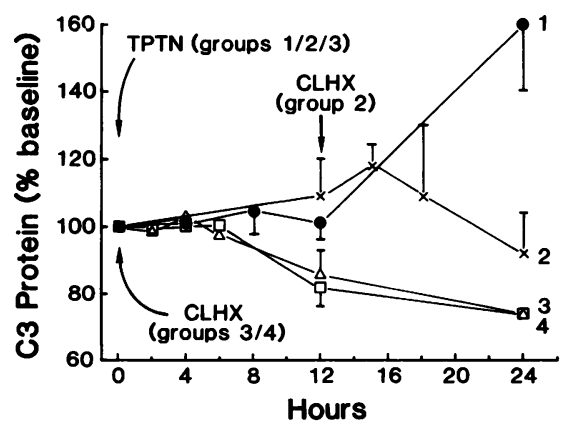

Figure 5. Cycloheximide (CLHX) inhibits the C3 acute phase response to turpentine pleurisy. Group $1(n=4)$ received TPTN only. Group $2(n=2)$ received cycloheximide 12 h post-TPTN, group 3 ( $n$ $=8$ ) received cycloheximide and TPTN at the same time, and group 4 received cycloheximide only $(n=4)$.

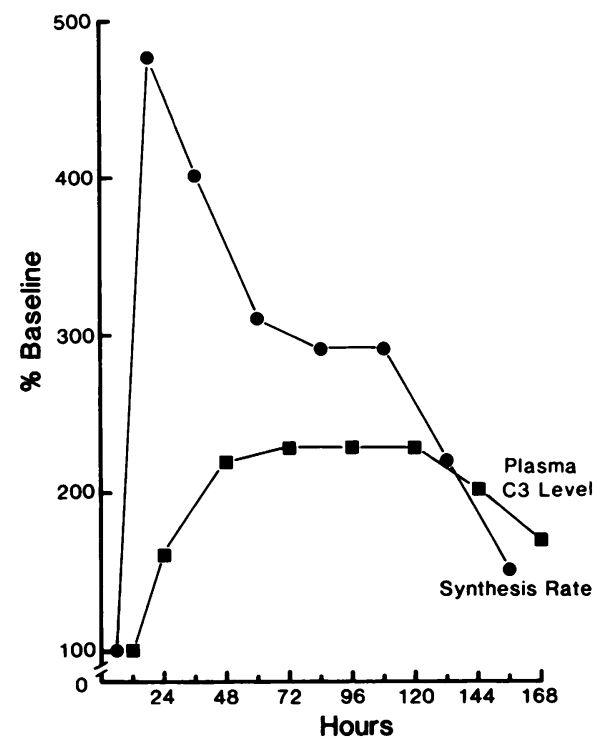

Figure 6. Plasma C3 concentrations and estimated synthesis rates during turpentine pleurisy.

which could explain the slightly larger $\bar{U} / \bar{X}$ ratio after turpentine injection, we submitted a sample of 6-h pleural fluid to crossed immunoelectrophoresis against goat anti-rabbit C3. Fig. 7 shows the result where the arc $a$ represents the native fraction and $b$ the cleaved molecule, indicating that activation had occurred during this early stage of the pleurisy. Similar techniques showed no fragments in the 6-h plasma sample.

\section{Discussion}

The induction of turpentine pleurisy, a local inflammatory process in the rabbit, was followed by a 2.3 -fold increase in the plasma C3 concentration. This was the result of measurable alterations in all three parameters of protein metabolism: synthesis, distribution, and catabolism. Distribution was the first parameter to be altered. After turpentine was injected into the right pleural cavity, a shift of $\sim 20 \%$ of the circulating C3 into that pleural space occurred within the first $24 \mathrm{~h}$ after injection.

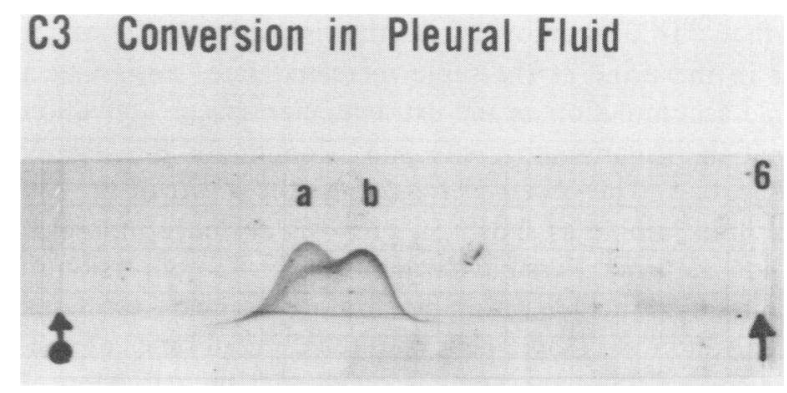

Figure 7. C3 cleavage in pleural fluid. By crossed immunoelectrophoresis against goat anti-rabbit $\mathrm{C} 3,6$-h pleural fluid shows two arcs: $a$ represents the native molecule, whereas $b$ is cleaved $C 3$. 
Since ${ }^{131}$ I-RSA appeared in the pleural space in the same proportions as the ${ }^{125} \mathrm{I}-\mathrm{C} 3$, it seems likely that nonspecific local permeability changes rather than specific transport mechanisms were involved. Spector and Willoughby (20) showed that similar permeability changes occurred in the first $6 \mathrm{~h}$ after turpentine injection into the pleural space of the rat. Based on the observation that the accumulation of pleural fluid was inhibited by pretreating the animals with a combination of mepyramine maleate and sodium salicylate, they concluded that the turpentine did not act directly on the vessel walls of the pleural cavity. We assume that in our experiments similar mechanisms resulted in the nonspecific influx of $\mathrm{C} 3$ and other proteins into the rabbits' pleural cavities, forming the inflammatory exudate and accounting for the observed loss of iodinated C3 from the circulation. The phase of increased permeability and influx of circulating proteins in the pleural cavity seems to be limited to the first $24 \mathrm{~h}$ after the injection of turpentine. Fig. 4 shows that after this time period the slope of the ${ }^{125}$ I-plasma C3 clearance curve returned parallel to the pre-injection slope. Evidence for a shift of circulating $\mathrm{C} 3$ into the pleural cavity was also found by analyzing the two plasma clearance curves during steady state and inflammation (Table III). During inflammation, the intravascular space $\left(C_{1}\right)$ decreased, whereas the extravascular space $\left(C_{2}\right)$ was enlarged and the rate of extravascular accumulation $\left(j_{1} / j_{2}\right)$ increased. These changes were not statistically significant.

Two methods were used to determine the FCR during inflammation. The plasma ${ }^{125} \mathrm{I}-\mathrm{C} 3$ clearance curve was analyzed to determine the sum of the catabolic rate and the undirectional flux into the pleural cavity. The ratio between the urinary excretion and the mean plasma activity was an expression of the true FCR. The comparative curve analysis of steady state conditions and inflammation in the same animal (Table III) showed that by this method there was a change in the PCR of almost $30 \%$. The obvious fact that our model does not involve a steady state of inflammation limits the validity of the results to a gross comparison between normal conditions and inflammation. For the curve analysis method this is due to the fact that the entire plasma clearance curve is needed for calculation of the parameters. Consistent $\bar{U} / \bar{X}$ ratios can be obtained only after a total body equilibration of the radiolabeled compound in reached, and this occurs only after $48 \mathrm{~h}$ for ${ }^{125} \mathrm{I}-\mathrm{C} 3$. The higher PCR shows that ${ }^{125} \mathrm{I}-\mathrm{C} 3$ is removed from the circulation but does not appear in the urine at the same increased rate, suggesting a probable accumulation in the extravascular space. Activation of $\mathrm{C} 3$ at the inflammatory site may account for the slightly increased $\bar{U} / \bar{X}$. The observed fragmentation of $\mathrm{C} 3$ in the $6-\mathrm{h}$ pleural fluid sample as shown in Fig. 7 is evidence that such activation occurred. Possible mechanisms for C3 conversion in the pleural fluid include action by enzymes released from lysed cells, activation of complement by altered membranes or subcellular constituents, and enzymes generated by activation of coagulation and fibrinolytic pathways.

The third parameter of protein metabolism, synthesis, was determined indirectly. During steady state the synthesis rate is equal to the FCR. During turpentine pleurisy, however, a 2.3fold increase of the plasma $\mathrm{C} 3$ level after a 12-h lag period was observed (Fig. 6). Possible reasons for the rise in the plasma C3 concentration are increased synthesis, decreased catabolism, and redistribution from the extravascular to the intravascular compartment. As we have shown above, the FCR was accelerated rather than decreased. Redistribution and decreased catabolism were also ruled out by the cycloheximide experiments summarized in Fig. 5, which showed that inhibition of protein synthesis blocked the increase in C3 concentration. This left increased protein neosynthesis as the reason for the observed rise in the plasma $\mathrm{C} 3$ concentration.

As Atencio and Reeve $(4,14)$ have shown, it is possible to calculate synthesis rates during conditions in which the plasma concentrations change and the exchange ratios remain constant. For the calculation of the increase in the $\mathrm{C} 3$ synthesis rate during turpentine pleurisy, we used the PCR and the altered ratios between the intra- and extravascular compartments (Table III). In doing so, our results may have been too low for the early phases of inflammation and too high for the later phases, but we feel that they adequately illustrate the pattern. A fivefold increase of the C3 synthesis rate was observed following a 12$\mathrm{h}$ lag period after turpentine injection (Fig. 6). A change of this magnitude caused the plasma C3 concentration to rise to $160 \%$ of baseline within $12 \mathrm{~h}$ and to $230 \%$ of baseline over the next $48 \mathrm{~h}$. It is possible that the initial 12-h lag period was needed for the development of local inflammation and the transmission of a signal to increase the $\mathrm{C} 3$ synthesis from the site of inflammation to the production site of the acute phase proteins, most likely the liver.

The interpretation of changes in metabolism during inflammation depends on the validity of using purified $\mathrm{C} 3$ protein covalently linked to ${ }^{125}$ I to determine rates of synthesis, catabolism, and distribution of this protein. The methods here described were initially worked out by Mathews (13) and have been extensively applied and modified for studies of the metabolism of albumin and fibrinogen in the rabbit by Reeve and coworkers $(4,14-16,21)$. Furthermore, many other proteins have been iodinated in order to determine various metabolic parameters. Data obtained by these methods have been shown to be reproducible and have been confirmed by other, unrelated methods.

A problem specifically related to the work with complement components is the maintenance of biological activity during the purification and iodination procedures. Even though C3 fragments were not detected in the purified preparations by means of crossed immunoelectrophoresis or SDS-PAGE, it is possible that any preparation of purified rabbit $\mathrm{C} 3$ contains a certain fraction of inactivated material. This inactivation could be either the result of cleavage or the formation of $\mathrm{C} 3 \mathrm{~b}$-like $\mathrm{C} 3$, as described by Pangburn et al. (22). A rapidly cleared fraction of radioactivity bound to $\mathrm{C} 3$ protein, as determined by TCA precipitation, was consistently a part of the plasma clearance curves of our experiments. Although enzyme inhibitors were added to all buffers throughout the purification process (see Methods), 
partial activation of $\mathrm{C} 3$ was likely. It was impossible to determine the percentage of the inactivated fraction since the detection of cleaved C3 in the purified preparation was limited by two problems. First, the hemolytic assay for rabbit C3 is much less sensitive than the assay for the human component (6). Second, when the specific hemolytic activities of the purified and the starting material were compared, in all cases activity of the purified preparation was higher because of the presence of natural inhibitors of $\mathrm{C} 3$ in normal rabbit plasma (6). Further opportunities to damage the $\mathrm{C} 3$ molecule are present in the procedure of radioiodination. The method chosen in these studies is believed to be less damaging than the chloramine-T method (9) since effective binding of the iodine to the protein is achieved with a lower chloramide-to-protein ratio than when chloramine$T$ is used. The combination of the purification procedure with the method of radioiodination made it likely that the preparations injected into the rabbits contained a small but significant fraction of radiolabeled C3 fragments. This conjecture is supported by the work of Alper and Ruddy. Alper and coworkers (23) found that ${ }^{131} \mathrm{I}-\mathrm{C} 3$ fragments were cleared from the circulation of volunteers at a very rapid rate, distinctly different from the clearance rates observed for the native material. Ruddy et al. (10), who reviewed 144 studies of C3 metabolism in humans, pointed out that the rapidly cleared fraction of the radioactivity reported by some investigators represented iodinated C3 fragments that were metabolized immediately after injection. They were able to link the size of this pseudocompartment to the loss of specific hemolytic activity before the injection. The plasma clearance curves of our experiments were corrected by the removal of the rapidly cleared fraction as recommended by Ruddy et al. (10). The method of biological screening, as described by Charlesworth and Williams (17) failed to show an advantage over direct injection of the ${ }^{125} \mathrm{I}-\mathrm{C} 3$. It is possible that the persistence of a rapidly cleared fraction after the biological screening was due to cleavage of $\mathrm{C} 3$ during reactions related to the exchange transfusion, such as hypovolemic shock in the donor, transfusion reactions in the recipients, and the introduction of tissue factors during the injection.

With the above-mentioned limitation of our results in mind, we compared the normal metabolic parameters of homologous C3 in the rabbit with those in humans $(10,23,28)$ and those of human C3 in rabbits (17) (Table IV). The rates of C3 metabolism in the rabbit are comparable to those in man. The similarity between our data and those of Charlesworth et al. (17) suggests that heterologous and homologous C3 are processed alike by the rabbit during normal steady-state conditions. When compared with IgG and albumin, C3 has a relatively high rate of metabolism (Table V). This may be partially explained by the fact that $\mathrm{C} 3$ is the substrate for not only the specific C3 convertases of the classical and alternative pathway, but also for a number of proteases not specific for the complement pathway.

It is rare to find studies that compare all three parameters of protein metabolism (synthesis, distribution, and catabolism) during local inflammation with the normal steady state. Chelladurai et al. (3) induced turpentine myositis in rabbits and
Table IV. FCRs and Synthesis Rates of Normal C3 Turnover in Humans and Rabbits

\begin{tabular}{|c|c|c|c|c|}
\hline Reference & $\begin{array}{l}\text { C3 } \\
\text { source }\end{array}$ & Species & FCR/h & $\begin{array}{l}\text { Synthesis } \\
\text { rate }\end{array}$ \\
\hline & & & & $m g / k g / h$ \\
\hline $\begin{array}{l}\text { Alper and Rosen, } \\
1967 \text { (23) }\end{array}$ & Human & Human & $2.3 \pm 1.0$ & $1.4 \pm 0.5$ \\
\hline $\begin{array}{l}\text { Petz et al., } 1968 \\
\quad(28)\end{array}$ & Human & Human & $2.1 \pm 0.3$ & $1.2 \pm 0.1$ \\
\hline $\begin{array}{l}\text { Ruddy et al., } \\
\qquad 1979(10)\end{array}$ & Human & Human & $1.7 \pm 0.3$ & $0.7 \pm 0.2$ \\
\hline $\begin{array}{l}\text { Charlesworth and } \\
\text { Williams, } 1974 \\
\text { (17) }\end{array}$ & Human & Rabbit & $2.4-2.8$ & NR \\
\hline This study & Rabbit & Rabbit & $2.7 \pm 0.3$ & $1.0 \pm 0.2$ \\
\hline
\end{tabular}

NR, not reported.

found that the normally very high FCR for CRP was not influenced by this inflammatory process. Atencio (24) injected typhoid vaccine into NZW rabbits and observed that plasma fibrinogen increased to $216 \%$ of baseline within $20 \mathrm{~h} .{ }^{125} \mathrm{I}-\mathrm{fi}-$ brinogen was rapidly cleared from the circulation but did not appear in the urine at the same rate, suggesting an accumulation of fibrinogen or its split products in the interstitial fluids due to temporarily increased vascular permeability. Lerner et al. (25) showed clearance of 18.5-19.5\% of circulating ${ }^{131}$ I-fibrinogen after the intravenous injection of bacterial lipopolysaccharide. Takahashi et al. (11) measured the incorporation of ${ }^{14} \mathrm{C}$-amino acids into $\mathrm{C} 9$ after the intramuscular injection of turpentine into mice and found a fivefold increase in the synthesis rate, but this method does not allow any assessment of the distribution and catabolism.

Reeve and Franks (26) have divided the acute phase response of fibrinogen into four stages. The first stage is a brief quiescent period varying in time with the stimulus chosen. In the second

Table V. Metabolism of Rabbit Plasma Proteins Compared with $C 3$

\begin{tabular}{|c|c|c|c|c|}
\hline Protein (Reference) & $\begin{array}{l}\text { Molecular } \\
\text { weight }\end{array}$ & Half-life & FCR & $\begin{array}{l}\text { Acute } \\
\text { phase } \\
\text { protein }\end{array}$ \\
\hline & & $d$ & $m g / k g / d$ & \\
\hline Albumin (21) & 67,000 & 7.9 & 0.235 & - \\
\hline $\operatorname{IgG}(29,30)$ & 150,000 & 6.0 & 0.096 & - \\
\hline C3 (this study) & 176,500 & 1.7 & 0.648 & + \\
\hline C5 (31) & 170,800 & 1.5 & 0.450 & + \\
\hline Factor XII (32) & 95,000 & 1.9 & 0.624 & $?$ \\
\hline Fibrinogen (4) & 340,000 & 2.6 & 0.410 & + \\
\hline Ceruloplasmin (33) & 151,000 & 2.3 & NR & + \\
\hline CRP (3) & 140,000 & 0.2 & 3.816 & + \\
\hline
\end{tabular}

NR, not reported. 
stage, a steep rise in plasma fibrinogen levels is characterized by a rapid burst of fibrinogen synthesis, often as high as 1020-fold. Significant changes in the catabolic rate often are not seen but may follow the stimulation of efflux pathways, as seen after bacterial lipopolysaccharide injection $(24,25)$. The search for stimulators of fibrinogen synthesis revealed the role of ACTH as discussed by Atencio et al. (4). During the third stage of the fibrinogen acute phase response, plasma fibrinogen fluctuates about a raised level. In this and the previous phase the plasma concentration depends on the interaction between mechanisms altering fibrinogen efflux from the intravascular space, and those stimulating synthesis. The fourth stage is the slow return to prestimulation conditions, characterized by a decrease of the synthesis rate as well as the return of the efflux constants to normal.

Our data suggest that during turpentine pleurisy the normal metabolic parameters of $\mathrm{C} 3$ in the rabbit undergo changes similar to those described above. A shift of circulating C3 into the site of inflammation occurred, as did a small increase in the catabolism. This was offset early by a fivefold acceleration in the synthesis rate, resulting in a 2.3-fold increase of the plasma C3 level. The methodology used in the studies here reported allows only a rough estimate of the changes in the synthesis rate. The changes found were similar to those reported for another component of complement, $\mathrm{C} 9$, in a different species with unrelated methods (5). The fact that a systemic acute phase response of C3 synthesis followed local induction of inflammation suggests that a locally produced signal reaches the site of $\mathrm{C} 3$ production, inducing the observed increase in synthesis. For fibrinogen, Chen (26) showed that denervating the rabbit ear did not inhibit the acute phase response to ear burn, whereas arresting the circulation did. More recently Sipe et al. (27) showed that interleukin I may fulfill the requirements for the circulating signal to induce increased synthesis of serum amyloid A, an APP in the mouse. The regulation of $\mathrm{C} 3$ metabolism is important in maintaining the balance of host defense mechanisms, and we are currently pursuing further studies to identify and characterize the messenger(s) that participate in this process.

\section{Acknowledgments}

The authors thank Dr. E. B. Reeve for his continuous advice, Drs. C. A. Alper, P. M. Henson, and R. B. Johnston, Jr. for their critical review and Dr. R. P. Martin for his editorial comments, as well as Carole Morrill for the preparation of this manuscript.

This study was supported by National Institutes of Health grants AI-17286, AM-26604, and HL-21565.

\section{References}

1. Pepys, M. B., M. L. Baltz, R. Mussalam, and M. J. Doenhoff. 1980. Serum protein concentrations during Schistosoma mansoni infections in intact and T-cell deprived mice. I. The acute phase proteins, C3 and serum amyloid P component (SAP). Immunology. 39:249-254.

2. Hartveit, F., W. Borve, and S. Thunold. 1973. Serum complement levels and response to turpentine inflammation in mice. Acta Pathol. Microbiol. Immunol. Scand. Sect. A Pathol. 286(Suppl.):54-59.
3. Chelladurai, M., S. S. MacIntire, and I. Kushner. 1983. In vivo studies of serum C-reactive protein turnover in rabbits. J. Clin. Invest. 71:604-610.

4. Atencio, A. C., P. Y. Chao, A. Y. Chen, and E. B. Reeve. 1969. Fibrinogen response to corticotropin preparations in rabbits. Am. J. Physiol. 216:773-780.

5. Takahashi, M., S. Kawachi-Takahashi, and K. Yamamoto. 1974. Synthesis of the ninth component of guinea pig complement (C9) in response to experimentally induced inflammation. Int. Arch. Allergy Appl. Immunol. 47:887-897.

6. Giclas, P. C., P. J. Keeling, and P. M. Henson. 1981. Isolation and characterization of the third and fifth component of rabbit complement. Mol. Immunol. 18:113-123.

7. Mancini, G., A. O. Carbonara, and J. F. Heremans. 1965. Immunochemical quantitation of antigens by single radial immunodiffusion. Immunochemistry. 2:235-254.

8. Laurell, C. B. 1966. Quantitative estimation of proteins by electrophoresis into agar containing antibodies. Anal. Biochem. 15:45-48.

9. Fraker, P. J., and J. C. Speck. 1978. Protein and cell membrane iodination with a sparingly soluble chloramide, 1,3,4,6-Tetrachloro$3 \alpha, 6 \alpha$-diphenylglucouril. Biochem. Biophys. Res. Commun. 80:849-857.

10. Ruddy, S., C. B. Carpenter, K. W. Chin, J. N. Knostman, N. A. Soter, O. Gotze, H. J. Muller-Eberhard, and K. F. Austen. 1979. Human complement metabolism: an analysis of 144 studies. Medicine (Baltimore). 54:165-178.

11. Kopaniak, M. M., K. D. Issekutz, C. E. Borrowes, and H. Z. Movat. 1980. The quantitation of hemorrhage in the skin. Measurement in the microcirculation in inflammatory lesions and related phenomena. Proc. Soc. Exp. Biol. Med. 163:126-131.

12. Sahn, S. A., and D. E. Potts. 1978. Turpentine pleurisy in rabbits: a model of pleural fluid acidosis and low fluid glucose. Am. Rev. Respir. Dis. 118:893-901.

13. Mathews, C. M. E. 1957. The theory of tracer experiments with ${ }^{131}$ I labelled plasma proteins. Phys. Med. Biol. 2:36-53.

14. Atencio, A. C., and E. B. Reeve. 1965. Studies on the metabolism and distribution of fibrinogen in young and older rabbits: II Results. $J$. Lab. Clin. Med. 66:20-33.

15. Atencio, A. C., H. R. Bailey, and E. B. Reeve. 1965. Studies on the metabolism and distribution of fibrinogen in young and older rabbits. I. Methods and models. J. Lab. Clin. Med. 66:1-19.

16. Reeve, E. B., and Y. Chen. 1973. Studies with a mass balance method of measuring fibrinogen synthesis. In Protein Turnover. Ciba Foundation Symposium. Elsevier/North Holland, Excerpta Medica, Amsterdam. Vol. 9. 91-111.

17. Charlesworth, J. A., D. G. Williams, and P. Naish. 1974. Metabolism of radiolabelled C3: effects of in vivo activation in rabbits. Clin. Exp. Immunol. 16:445-452.

18. Foss, S. D. 1969. A method for obtaining initial estimates of the parameters in exponential curve fitting. Biometrics. 25:580-584.

19. Marquard, D. W. 1963. An algorithm for least squares estimations of non-linear parameters. J. Soc. Ind. Appl. Math. 4:431-441.

20. Spector, W. G., and D. A. Willoughby. 1959. The demonstration of the role of mediators in turpentine pleurisy in rats by experimental suppression of the inflammatory change. J. Path. Bact. 77:1-17.

21. Reeve, E. B., and J. E. Roberts. 1959. The kinetics of the distribution and breakdown of ${ }^{131} \mathrm{I}$-albumin in the rabbit. J. Gen. Physiol. 43:415-444.

22. Pangburn, M. K., R. D. Schreiber, H. J. Muller-Eberhard. 1981. Formation of the initial C3 convertase of the alternative complement pathway. J. Exp. Med. 154:856-867.

23. Alper, C. A., and F. S. Rosen. 1967. Studies of the in vivo 
behavior of human $\mathrm{C} 3$ in normal subjects and patients. J. Clin. Invest. 46:2021-2034.

24. Atencio, A. C. 1967. Studies on the regulation of fibrinogen synthesis in the rabbit. Ph.D. thesis. University of Colorado, Boulder, CO. 72-76.

25. Lerner, R. G., S. I. Rappaport, J. K. Sieman, and J. M. Spitzer. 1968. Disappearance of fibrinogen- ${ }^{131} I$ after endotoxin: effects of a first and second injection. Am. J. Physiol. 214:532-537.

26. Reeve, E. B., and J. J. Franks. 1974. Fibronogen synthesis, distribution and degradation. Sem. Thromb. Hemostasis. I:129-183.

27. Sipe, J. D., S. N. Vogel, M. B. Sztein, M. Skinner, and A. S. Cohen. 1982. The role of Interleukin $I$ in acute phase serum amyloid A (SAA) and serum amyloid P (SAP) biosynthesis. Ann. NY Acad. Sci. 398:137-151.

28. Petz, L. D., D. J. Fink, E. A. Letzky, H. H. Fudenberg, and H. J. Muller-Eberhard. 1968. In vivo metabolism of complement. I.
Metabolism of the third component (C3) in acquired hemolytic anemia. J. Clin. Invest. 47:2469-2484.

29. Spiegelberg, H. L., and W. O. Weigle. 1964. The catabolism of homologous and heterologous $7 \mathrm{~S}$ gammaglobulin fragments. J. Exp. Med. 121:323-338.

30. Waldman, T. A., R. M. Blaese, and W. Strober. 1970. Physiological factors controlling immunoglobulin metabolism. In Plasma Protein Metabolism. M. A. Rothchild and T. A. Waldman, editors. Academic Press, Inc., New York. 269-286.

31. Giclas, P. C. 1980. In vivo metabolism of $\mathrm{C5}$ in the rabbit. Fed. Proc. 39:700. (Abstr.)

32. Wiggins, R. C., A. M. Campbell, and D. H. DeHeer. 1982. Distribution and turnover of ${ }^{125} \mathrm{I}$-Hageman factor in the rabbit. Fed. Proc. 41:704. (Abstr.)

33. Aisen, P., A. G. Morell, S. Albert, and I. Sternlieb. 1974. Biliary excretion of ceruloplasmin copper. Nature (Lond.). 203:873-874. 